\title{
Pattern of Internet Usage and Addiction among Students of Private Medical Colleges in Dhaka City, Bangladesh
}

\author{
Subrina Ahmed ${ }^{1}$, Nuhad Raisa Seoty ${ }^{1}$, Nawzia Yasminn', Mohammad Niaz Morshed Khan ${ }^{1 *}$
}

1 Department of Public Health,

State University of Bangladesh,

Bangladesh

*Corresponding author's email:

niazmkhan30@gmail.com

Received: 23 February 2019

Accepted: 30 April 2019

How to Cite:

Khan, M. N., Ahmed, S., \& Seoty, N. R. (2019). Pattern of internet usage and addiction among private medical colleges students in Dhaka City, Bangladesh. Borneo Journal of Medical Sciences (BJMS), 13 (2), 25-34. Retrieved from https:// jurcon.ums.edu.my/ojums/index.php/bjms/ article/view/1720

Keywords: internet use, addiction, medical students, Bangladesh

\section{ABSTRACT}

Internet addiction specifies to the extreme use of the internet which sequentially causes problems in relationship, health and professional aspects. The current study attempted to find out the pattern of internet use and internet addiction-related behaviour among the students of private medical colleges in Dhaka City, Bangladesh. A cross-sectional study was executed in three private medical colleges in Dhaka city. A total of $\mathbf{3 5 0}$ medical students were recruited as study participants by employing a simple random sampling technique. Data was collected through a selfadministered semi-structured questionnaire on sociodemographic and internet use related activities. Internet addiction-related data were collected by using Young's Internet Addiction Test (IAT) Scale. The data were analysed using the Statistical Package for Social Science (SPSS version 20). Descriptive and inferential statistics using the Chi-square test was conducted. P-value $<0.05$ was considered as significant. The findings show that $73.7 \%$ of study participants were female and the rest were male, with a mean age of 21.1 years. The percentage of students used the internet more than 10 times per day was $37.4 \%$ followed by 5 - 10 times per day which was $35.1 \%$ and less than five times per day with $27.4 \%$ students. A total of $44.3 \%$ students reported that they spent $1-3$ hours per day for internet usage followed by $37.7 \%$ use $4-8$ hours per day and $18 \%$ reported more than 8 hours per day. A total of $43.7 \%$ students mentioned that they used the internet for entertainment, while $40 \%, 9.7 \%$ and $6.6 \%$ reported for time passing, social networking, and academic purposes respectively. Overall, $76.9 \%$ of students had internet addiction either in any form, $62.6 \%$ had moderate internet 
addiction or problem use, or $14.3 \%$ had severe internet addiction. This study concludes that the characteristics of internet use among this population are diverse and the prevalence of internet addiction found to be considerably higher compared to other Asian countries.

\section{INTRODUCTION}

The information technology revolution of the present era is primarily based on the internet. It has permeated into our lives to such an extent that life without the internet seems meaningless ${ }^{1}$. The internet is a worldwide system of interconnected computer networks that has revolutionized the information age, allowing humans, to gain access to an unlimited amount of information as well as changing the way humans communicate with each other ${ }^{2,3}$. Worldwide 4.1 billion people use the internet as of December 2018 and Asia has the highest number of users among all the countries. Among the Asian countries, China has the topmost number of internet users followed by India and Bangladesh stood in 5th position ${ }^{4}$. According to the Bangladesh Telecommunication Regulatory Commission (BTRC), a total of 91.34 million people use the internet ${ }^{5}$.

Studies showed that despite having remarkable constructive benefits of the internet, its misuse and excessive use could be addictive and pathological ${ }^{6}$. Internet addiction can be described as an inability to restrict one's internet use despite harmful consequences ${ }^{7,8}$ and which continues to a prolonged period of time ${ }^{9}$. Internet gaming is considered as a disorder in the Statistical Manual for Mental Disorders (DSM-5) that demands more research ${ }^{10}$. Internet use can affect different domains such as physical, social, occupational, interpersonal and psychological of the individual's life. Uncontrolled use of the internet has emerged as a concern worldwide especially among young people. Evidence shows that the volume of time students spend on the internet for educational and noneducational purposes significantly influences their future career ${ }^{11}$.
Variation in the prevalence of internet addiction is found worldwide. Studies conducted among college students in the United Kingdom (UK) and the United States (US) revealed that $18.3 \%$ and $4.25 \%$ prevalence of internet addiction respectively. Apart from the UK and the US, $17.3 \%, 0.7 \%$ and $17.9 \%$ of college students found addicted to the internet in Qatar, India, and Taiwan respectively ${ }^{12}$.

Individuals who pass hours on the internet ultimately start to see its impact on their daily lives. This addiction slows down people's activities and as they get engrossed in the internet it turned into an issue ${ }^{13}$.

Substantial evidence shows that the consequences of internet addiction can also make real damage to an individual's health like internet addiction disorder (IAD) and guilt feelings, poor time management, depression, anxiety, hostility, psychosis, social isolation, substance use disorders, just like alcoholism or drug abuse. Excessive internet use can also lead to desk-bound lifestyles, obesity, and poor physical fitness. Further manifestations include carpal tunnel syndrome, dry eyes, back pain, migraine, poor personal hygiene $e^{14,15}$.

The university campuses are being equipped with wireless, with no cost and unrestricted access to the internet. It is often considered that due to the complicated and stressful nature of academic course curricula undergraduate medical students become susceptible to internet addiction ${ }^{16}$.

Medical students are the future primary healthcare providers and therefore if the future doctors get addicted to the internet, then it might cause more harm. In addition, it could also hamper their career, lifestyle, and personality as doctors. A study conducted among Iranian medical students found $27.5 \%$ prevalence of internet addiction with points higher than $50^{17}$. 
Considering the growing anecdotal evidence about the overuse of the internet by the medical students, it was necessary to investigate the pattern, prevalence, severity and the corresponding problems caused by the internet addiction among students of private medical colleges in Dhaka City, Bangladesh.

\section{MATERIALS AND METHODS}

This cross-sectional study was conducted in three private medical colleges in Dhaka city, Bangladesh, namely Bangladesh Medical College and Hospital, Medical College for Women and Hospital, and Anwer Khan Modern Medical College and Hospital from April 2018 to July 2018. There are 36 government recognized private medical colleges in Bangladesh and 23 are located in Dhaka city ${ }^{18}$. Among these medical colleges, three medical colleges were selected for this study. A total of 350 MBBS students (2nd, 3rd and 4th years) both male and female using the internet at least for one year were enrolled, employing simple random sampling technique. The 1st year students were excluded since they were in the adaptation phase and 5th (final) year students were in a transition phase in their academic settings. Prior approval was taken from the ethical review committee of the State University of Bangladesh and earlier permission was taken from respective medical colleges' authority. The objectives of the study were briefed to the students then the written informed consent was taken during the enrollment of study participants. Data were collected by trained data collectors. After ensuring confidentiality, data were collected by using a pretested selfadministered semi-structured questionnaire which contained three different parts i.e. socio-demographic, academic and internet use related data and Internet Addiction Test by using a scale developed by Kimberly S. Young ${ }^{19}$. The Young's Internet Addiction Questionnaire consists of 20 items with responses on a 5-point Likert scale which evaluates the severity of self-reported compulsive internet use. The total score ranging from 20 to 100 was categorized into none $(0-30)$, mild $(31-49)$, moderate $(50-79)$ and severe (>80) internet addiction. The questionnaire was developed initially in English and then translated into native language i.e. Bengali. Lecture galleries of medical colleges were selected for data collection considering suitability and ensuring the quality of data collection. Data were analyzed by using SPSS version 20.0. Descriptive and inferential statistics using the Chi-square test was conducted. $P$-value $<0.05$ was counted as significant.

\section{RESULTS}

\section{Socio-economic Characteristics}

The study findings revealed that majority of the participants (68.9\%), were in the age group of 20 - 22 years followed by more than 22 years (17.4\%), and less than 20 years (13.7\%). The mean age of the study participants was 21.1 years $( \pm 1.5)$. Among the 350 study participants, $258(73.7 \%)$ were female and the rest of the 92 students were male (26.3\%). The income of majority of family was between $<5,00,000$ Bangladeshi Taka (BDT) per month $(59.7 \%)$ and the mean income were 6, 29, $397( \pm 9,50,113.1)$ BDT and the median income were 70,000 (Range: 10,000 - 50,00,000) BDT (Table 1). 
Table 1 Socioeconomic characteristics of the participants $(N=350)$

\begin{tabular}{|c|c|c|c|}
\hline Characteristics & Subgroup & Frequency & Mean $( \pm S D)$ \\
\hline \multirow{3}{*}{$\begin{array}{l}\text { Age of participants } \\
\text { (in years) }\end{array}$} & $<20$ Years & $48(13.7 \%)$ & $21.1( \pm 1.5)$ \\
\hline & $20-22$ Years & $241(68.9 \%)$ & \\
\hline & $>22$ Years & $61(17.4 \%)$ & \\
\hline \multirow[t]{2}{*}{ Gender } & Male & $92(26.3 \%)$ & \\
\hline & Female & $258(73.7 \%)$ & \\
\hline \multirow[t]{3}{*}{ Year of study } & 2nd Year & 115 (32.9\%) & NA \\
\hline & 3rd Year & $140(40.0 \%)$ & \\
\hline & 4th Year & 95 (27.1\%) & \\
\hline \multirow{4}{*}{$\begin{array}{l}\text { Monthly family income } \\
\text { (In Bangladeshi Taka) }\end{array}$} & $<5,00,000$ & 209 (59.7\%) & 629397.1 \\
\hline & & & $( \pm 950113.1)$ \\
\hline & $5,00,000-10,00,000$ & $102(29.1 \%)$ & \\
\hline & $>10,00,000$ & 39 (11.1\%) & \\
\hline
\end{tabular}

NA: Not Applicable

\section{Accessibility to the Internet}

Findings demonstrated that the vast majority $(94.6 \%)$ of the medical students used the internet through mobile phones and only $3.4 \%$ used their desktop computers for internet surfing. Regarding the type of connection used for internet browsing, $82.9 \%$ students reported that they used Wi-Fi connection due to userfriendliness and $14.3 \%$ mentioned about the mobile data-packs. Only two per cent used a broadband connection and remainders used by multiple connections (0.9\%). For Wi-Fi users, $12.5 \%$ and $11.6 \%$ students used internet in their living areas and college premises respectively, $75.6 \%$ mentioned about more than one facilities i.e. medical college campus, living area, and transports for internet use. Apart from that findings illustrated that majority (48\%) of the student visited once in a month, $17.4 \%$ visited twice in a month and $26 \%$ student visited once in a week to restaurants where they availed free Wi-Fi facility. The study also found that $48 \%$ students used free $\mathrm{Wi}-\mathrm{Fi}$ connection, $37.4 \%$ students reported that their internet expenditures were backed by their parents and $11.7 \%$ reported they themselves bore the costs (Table 2). 
Table 2 Accessibilities of internet use of the participants $(N=350)$

\begin{tabular}{|c|c|c|}
\hline Characteristics & Subgroup & Frequency \\
\hline \multirow[t]{4}{*}{ Device used for internet } & Desktop computer & $12(3.4 \%)$ \\
\hline & Tablet & $5(1.4 \%)$ \\
\hline & Mobile phone & $331(94.6 \%)$ \\
\hline & Multiple devices & $2(0.6 \%)$ \\
\hline \multirow[t]{4}{*}{ Types of internet use } & Broadband & $7(2.0 \%)$ \\
\hline & Mobile data pack & $50(14.3 \%)$ \\
\hline & $\mathrm{Wi}-\mathrm{Fi}$ & $290(82.9 \%)$ \\
\hline & Multiple internet & $3(0.9 \%)$ \\
\hline \multirow[t]{4}{*}{ Used free Wi-Fi facility } & College campus & $35(11.6 \%)$ \\
\hline & Living area & $38(12.5 \%)$ \\
\hline & Transport & $1(0.3 \%)$ \\
\hline & More than one place & $229(75.6 \%)$ \\
\hline \multirow[t]{4}{*}{ Visited restaurant having free Wi-Fi } & Once in a week & $91(26.0 \%)$ \\
\hline & Once in a month & $168(48.0 \%)$ \\
\hline & Twice in a month & $61(17.4 \%)$ \\
\hline & No Wi-Fi use in the restaurant & $30(8.6 \%)$ \\
\hline \multirow[t]{6}{*}{ Internet expenditure paid by } & Parents & $131(37.4 \%)$ \\
\hline & Brother & $5(1.4 \%)$ \\
\hline & Free Wi-Fi & $168(48.0 \%)$ \\
\hline & Self & $41(11.7 \%)$ \\
\hline & Uncle & $3(0.9 \%)$ \\
\hline & Others & $2(0.6 \%)$ \\
\hline
\end{tabular}

\section{Frequency of Internet Use and Time Spent} per Day

The study explored that a notable number (37.4\%) of students used the internet more than 10 times per day followed by $5-10$ times per day (35.1\%) and $27.4 \%$ students used less than five times per day. In terms of time spending for internet surfing, $44.3 \%$ of students reported that they spent $1-3$ hours per day, $37.7 \%$ students reported $4-8$ hours per day and rest $18 \%$ reported more than 8 hours per day (Figure 1). 


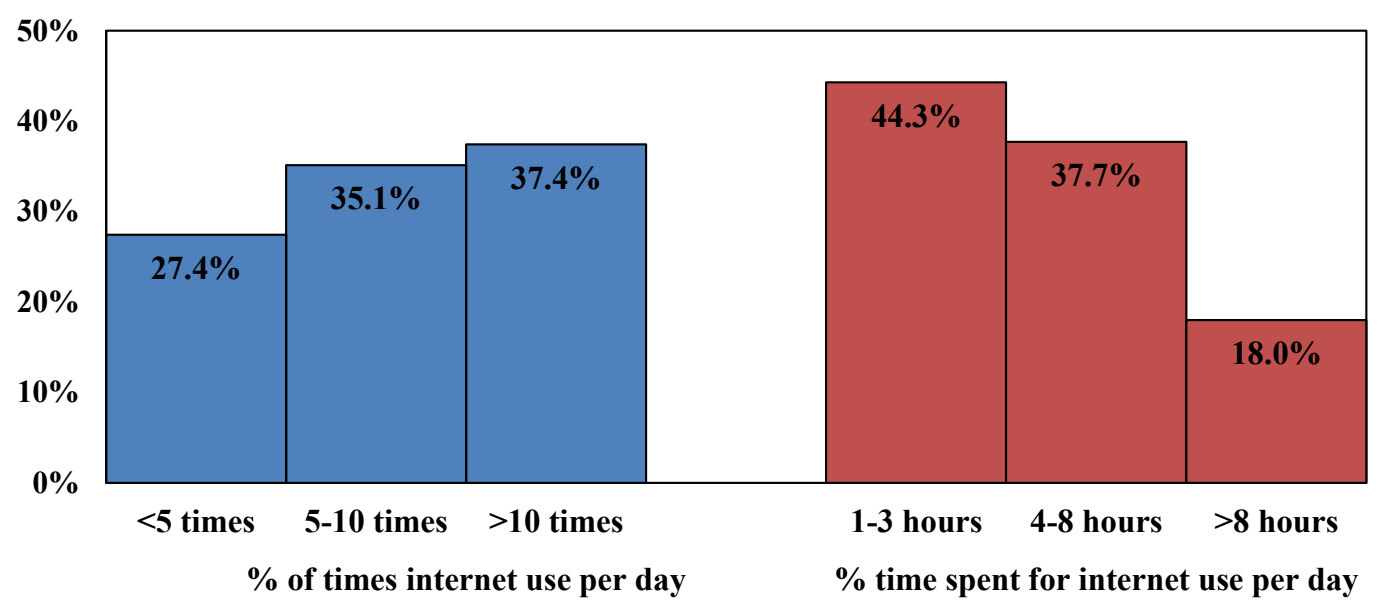

Figure 1 Frequency of internet use and time spent per day

\section{Reasons for Internet Use}

While inquiring about the purpose of internet use to study participants $43.7 \%$ mentioned that they used internet for getting entertainment, $40 \%$ reported for time passing, $9.7 \%$ and $6.6 \%$ cited for social networking and academic purposes respectively (Figure 2).

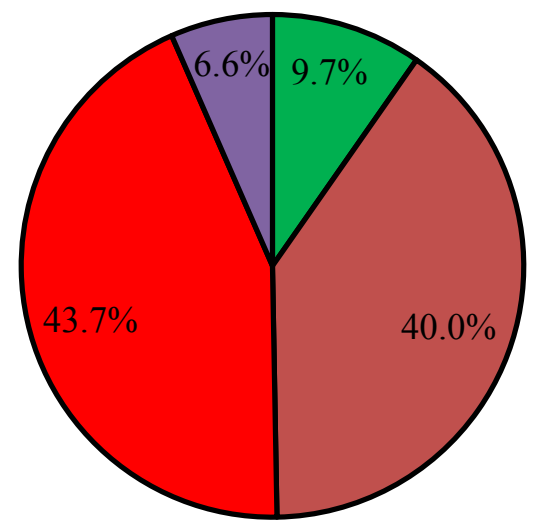
口Social networking
口Time pass
口Entertainment
口 Academic purposes

Figure 2 Reasons for internet use

\section{Time Spent for Using the Internet}

A good majority (82.9\%) of students highlighted that they spent time with their friends primarily through online chatting. On the other hand, $31.4 \%$ of students reported they did not feel the need for spending time physically with their family members due to having this online time spending facility. While, 9.1\% students reported that they have faced academic problem due to their internet using behaviour (Table 3).

Table 3 Spending time and problem of internet use of the participants $(N=350)$

\begin{tabular}{lcc}
\hline \multicolumn{1}{c}{ Characteristics } & Subgroup & Frequency \\
\hline Spending time & Yes & $240(68.6 \%)$ \\
with family & No & $110(31.4 \%)$ \\
$\begin{array}{l}\text { Spending time } \\
\text { with friends }\end{array}$ & Yes & $290(82.9 \%)$ \\
through online & No & $60(17.1 \%)$ \\
$\begin{array}{l}\text { chatting } \\
\text { Academic } \\
\text { problem }\end{array}$ & Yes & $32(9.1 \%)$ \\
& No & $318(90.9 \%)$
\end{tabular}

\section{Internet Addiction}

This study illustrated that overall $76.9 \%$ study participants have internet addiction problem either in any form. Further analysis showed that $62.6 \%$ students have moderate internet addiction, and $14.3 \%$ have a severe internet addiction. The rest (23.1\%) have a mild internet addiction (Figure 3 ). 


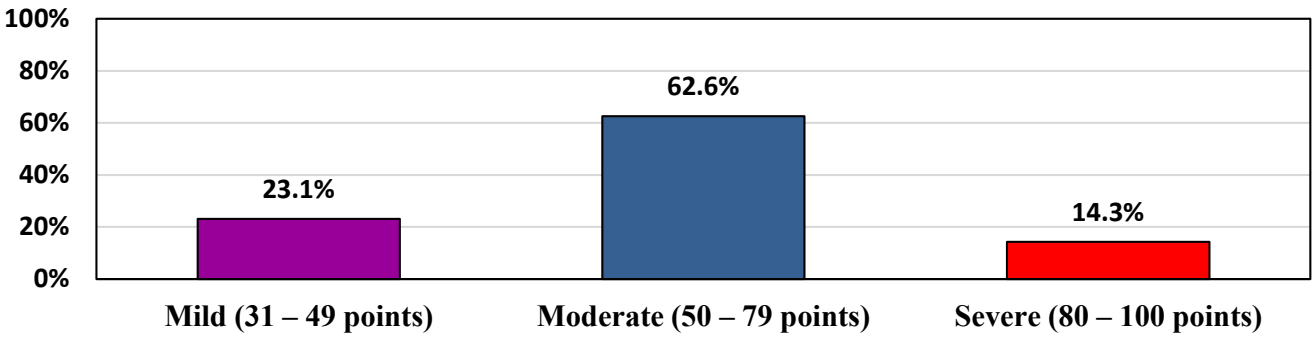

Figure 3 Severity of internet addiction

\section{Association of Internet Use and Addiction}

The study also explored the pattern of internet use and related addiction among the study participants. The finding showed that the students who have spent $4-8$ hours $(p<0.001)$ for internet use and not spending time with their family $(p<0.05)$, were addicted to the internet and they also had academic problems $(p<0.05)$. However, no significant association was found among gender, year of study, frequency of use of the internet, spending time with friends physically and through online chatting with internet addiction $(p>$ 0.05) (Table 4).

Table 4 Association with a pattern of internet use and internet addiction

\begin{tabular}{|c|c|c|c|c|}
\hline Variables & Normal students & Addicted students & Chi-Square $\left(\lambda^{2}\right)$ & $p$-value \\
\hline $\begin{array}{r}\text { Male } \\
\text { Female }\end{array}$ & $\begin{array}{l}23(25.0 \%) \\
58(22.5 \%)\end{array}$ & $\begin{array}{l}69(75.0 \%) \\
200(77.5 \%)\end{array}$ & 0.24 & $0.623^{\text {ns }}$ \\
\hline $\begin{array}{l}\text { 2nd Year } \\
\text { 3rd Year } \\
\text { 4th Year }\end{array}$ & $\begin{array}{l}31(27.0 \%) \\
24(17.1 \%) \\
26(27.4 \%) \\
\end{array}$ & $\begin{array}{l}84(73.0 \%) \\
116(82.9 \%) \\
69(72.6 \%) \\
\end{array}$ & 4.73 & $0.094^{\text {ns }}$ \\
\hline $\begin{array}{l}\text { Frequency use of internet } \\
\qquad \begin{array}{r}<5 \text { times } \\
5-10 \text { times } \\
>10 \text { times }\end{array}\end{array}$ & $\begin{array}{l}28(29.2 \%) \\
26(21.1 \%) \\
27(20.6 \%) \\
\end{array}$ & $\begin{array}{l}68(70.8 \%) \\
97(78.9 \%) \\
104(79.4 \%) \\
\end{array}$ & 2.71 & $0.258^{\text {ns }}$ \\
\hline $\begin{array}{l}\text { Time spent on the use of internet } \\
\qquad \begin{array}{r}1-3 \text { hours } \\
4-8 \text { hours } \\
>8 \text { hours }\end{array}\end{array}$ & $\begin{array}{l}53(34.2 \%) \\
27(20.5 \%) \\
1(1.6 \%)\end{array}$ & $\begin{array}{l}102(65.8 \%) \\
105(79.5 \%) \\
62(98.4 \%)\end{array}$ & 27.6 & $<0.001^{*}$ \\
\hline $\begin{array}{r}\text { Spending time with friends physically } \\
\text { Yes } \\
\text { No }\end{array}$ & $\begin{array}{l}45(23.2) \\
36(23.1)\end{array}$ & $\begin{array}{l}149(76.8) \\
120(76.9)\end{array}$ & 0.0007 & $0.979^{\text {ns }}$ \\
\hline Spending time with family & $\begin{array}{l}66(27.5) \\
15(13.6)\end{array}$ & $\begin{array}{l}174(72.5) \\
95(86.4)\end{array}$ & 8.2 & $0.004^{*}$ \\
\hline $\begin{array}{l}\text { Spending time with friends through } \\
\text { online chatting } \\
\qquad \begin{array}{l}\text { Yes } \\
\text { No }\end{array}\end{array}$ & $\begin{array}{l}65(22.4) \\
16(26.7) \\
\end{array}$ & $\begin{array}{l}225(77.6) \\
44(73.3)\end{array}$ & 0.5 & $0.477^{\text {ns }}$ \\
\hline Academic problem & $\begin{array}{l}2(6.2) \\
79(24.8)\end{array}$ & $\begin{array}{l}30(93.8) \\
239(75.2)\end{array}$ & 5.7 & $0.017^{*}$ \\
\hline
\end{tabular}

ns: Non-significant, ${ }^{*}$ : Significant at $p<0.05$ 


\section{DISCUSSION}

This study was conducted to evaluate the pattern and prevalence of internet addiction and the relevant problems emerging from the internet overuse among private medical students in Dhaka City. To our knowledge, this was the first study in Bangladesh to examine this issue among medical students. The result reflected that among the study participants, an overwhelming majority of the students used the internet through mobile phones by using free Wi-Fi connection. This might be the result of free and/or reduced internet charge as part of an emphatic effort of Bangladesh government to convert Bangladesh into a technologically advanced country by $2021^{20}$. In addition, this study found the increased duration of daily usage of internet surfing compared to other studies conducted among the same study population in other Asian countries $^{21,22}$. The study also revealed that $94.6 \%$ of participants used mobile phone for internet surfing, this finding is aligned with another study conducted in Auraganbad, India among medical interns ${ }^{23}$. Finding of this study also demonstrated that majority of study participants (43.7\%) reported that they used the internet mainly for getting entertainment which is not aligned with a previous study conducted in Bangladesh, where time pass was reported by the majority (57.3\%) of the student participants ${ }^{24}$. Although, that study participants were from different academic (i.e. non-medical student participants) and economic background that might have been a probable reason for this difference. Besides, this study found that only $6.6 \%$ of our study participants reported the reason for surfing was for educational purposes which were found to be much higher in the earlier studies (36.9\% and $15.30 \%$ ) conducted among the similar populations in India and Malaysia ${ }^{25}$, ${ }^{26}$. This finding indicates that a vast majority of private medical student participants have been using the internet for non-productive purposes which are alarming for both their academic career as well as for the nation since they will be the key health service providers of the country. Another important finding of this study was the high prevalence of internet addiction especially the level of severe addiction (14.3\%) in these study areas' medical students. When compared to other studies conducted among the similar populations in other parts of the world, it is evident that these study participants have a higher severity of addiction compared to them ${ }^{26-29}$. Evidence shows that severe internet addiction leads to the adverse physical effects like migraine or headache, less sleep, obesity, and backaches, negative psychological and social impacts ${ }^{24,26}$. This study finding also revealed that students who spent more than 8 hours of surfing per day, almost all of them (98.4\%) suffered from internet addiction. Furthermore, due to the higher proportion of internet addiction among these study participants, family time passing behaviour and academic performance were also reflected compromised. These findings are consistent with the findings from previous studies in other parts of the world as well ${ }^{25,26}$.

\section{LIMITATIONS}

Although this study collected data from three private medical colleges located at different areas of Dhaka city where students from different regions of the country attended for academic purpose, we could not maintain gender balance while recruiting the study participants, rather we had to enroll more female students compared to their male counterpart. Since among the three medical colleges, one was exclusively for female students and the remaining two medical colleges provided co-education. Therefore, female samples dominated the male samples. Future study needs to be conducted by overcoming this limitation. 


\section{CONCLUSION}

Thus, based on the results of this study it can be concluded that the characteristics of internet use among this population are diverse and the prevalence of internet addiction found to be considerably higher compared to other Asian countries. Therefore, policymakers, health professionals including mental health professionals and guardians should be aware of the spectrum of this problem. They should take into consideration the magnitude of this problem which might help them to design an appropriate intervention for the prevention and remedy of internet addiction for Bangladesh as well as other low- and middleincome countries in the world.

\section{CONFLICT OF INTEREST}

The authors declare that they have no competing interests in publishing this article.

\section{ACKNOWLEDGMENTS}

We acknowledge the support of the Department of Public Health of the State University of Bangladesh as well as to the study participants of three medical colleges for their valuable time and information.

\section{REFERENCES}

1. Matusitz J. (2007). The implications of the internet for human communication. Journal of Information Technology Impact 7 (1): $21-34$.

2. Salam A, Song CO, Mazlan NF et al. (2012). The professionalism of future medical professionals in Universiti Kebangsaan Malaysia (UKM) Medical Centre. Int Med J 19 (3): $224-228$.

3. Siraj HH, Salam A, Hasan NAB et al. (2015). Internet usage and academic performance: A study in a Malaysian public university. Int Med J 22 (2): $83-86$.
4. Stevens J. (2019). Internet stats and facts for 2019. Available from https://hostingfacts. com/internet-facts-stats/

5. BTRC. (2018). Internet subscribers in Bangladesh Dhaka: Bangladesh Telecommunication Regulatory Commission. Available from http://www. btrc.gov.bd/telco/internet

6. Widyanto L, Griffiths M. (2006). 'Internet addiction': A critical review. International Journal of Mental Health and Addiction 4 (1): $31-51$.

7. Griffiths M. (2000). Does Internet and computer "addiction" exist? Some case study evidence. Cyber Psychology and Behavior 3 (2): $211-218$.

8. Tang D, Wei F, Qin B, Liu T, Zhou M, editors. (2014). Coooolll: A deep learning system for twitter sentiment classification. Proceedings of the 8th international workshop on semantic evaluation (SemEval 2014).

9. Kardefelt-Winther D, Heeren A, Schimmenti A et al. (2017). How can we conceptualize behaviouraladdiction without pathologizing common behaviours? Addiction 112 (10): 1709 - 1715.

10. Poli R. (2017). Internet addiction update: Diagnostic criteria, assessment and prevalence. Neuropsychiatry 7 (1): 4 - 8 .

11. Egger O, Rauterberg M. (1996). Internet behavior and addiction. Semester thesis (Swiss Federal Institute of Technology, Zurich, 1996).

12. Mihajlov M., Vejmelka L. (2017). Internet addiction: A review of the first twenty years. Psychiatria Danubina 29 (3): 260 - 272.

13. Muniandy B. (2010). Academic use of internet among undergraduate students: A preliminary case study in a Malaysian university. International Journal of Cyber Society and Education 3 (2): 171 - 178.

14. PsychGuides. (2019). Computer/internet addiction symptoms, causes and effects. Available from https://www.psychguides. com/guides/computerinternet-addictionsymptoms-causes-and-effects/

15. Young KS, Rogers RC. (1998). The relationship between depression and internet addiction. Cyberpsychology \& Behavior 1 (1): 25 - 28.

16. Fatehi F, Monajemi A, Sadeghi A. (2016). Quality of life in medical students with internet addiction. Acta Medica Iranica 54 (10): $662-666$. 
17. Bangladesh Medical \& Dental Council. (2019). List of non-govt. medical colleges under Dhaka University.

18. Gorgich EAC, Moftakhar L, Barfroshan S, Arbabisarjou A. (2018). Evaluation of internet addiction and mental health among medical sciences students in the Southeast of Iran. Shiraz E-Medical Journal. 19 (1): e55561. doi: 10.5812/semj.55561.

19. Young KS. (1998). Internet addiction: The emergence of a new clinical disorder. Cyberpsychology \& Behavior 1 (3): 237 - 244.

20. Agency KIC. (2018). e-Government Master Plan for Digital Bangladesh. Dhaka: Department of Information and Communication Technology, Ministry of Post, Telecommunication and Information Technology, Government of the People's Republic of Bangladesh 2018.

21. Liu X, Bao Z, Wang Z. (2010). Internet use and internet addiction disorder among medical students: A case from China. Asian Social Science 6 (1): 28 - 34.

22. Dhok RS, Kadarkar KS, Doibale MK. (2016). Exploring levels of internet addiction among medical interns: A cross-sectional study. International Journal of Medical Science and Public Health 5 (11): 2341 - 2346.

23. R. SKD, Debata I. (2018). Study to assess internet usage patterns and prevalence of internet addiction among medical and engineering students of Bengaluru city. International Journal of Community Medicine and Public Health 5 (6): 2331 - 2337.
24. Professor D. Ahmadullah Mia P, Uddin M, Hasan M. (2015). Impact of internet use on young students. Dhaka, Bangladesh: University of Development Alternative (UODA).

25. Haque $M$, Rahman NAA, Majumder MAA et al. (2016). Internet use and addiction among medical students of Universiti Sultan Zainal Abidin, Malaysia. Psychology Research and Behavior Management 9: 297.

26. Sushma J, Ahmed M, Amrutha A. (2018). A study to assess internet addiction among undergraduate medical students of MMC\&RI, Mysore. International Journal of Community Medicine and Public Health 5 (7): $2984-2988$.

27. Chinatu-Nwankwo O. (2015). Prevalence of internet addiction among medical students in Abia State University, Uturu, Nigeria. Abia State University Medical Students' Association Journal 10 (1).

28. Pramanik T, Sherpa M, Shrestha R. (2012). Internet addiction in a group of medical students: A cross sectional study. Nepal Medical College Journal NMCJ 14 (1): 46 - 48.

29. Patil SD, Deshmukh JS, Dagdiya KR. (2017). Prevalence and pattern of internet addiction among medical students in Nagpur, Maharashtra. International Journal of Community Medicine and Public Health 4(7): $2412-2416$. 